\title{
ESTOQUE DE CARBONO E QUANTIFICAÇÃO DE SUBSTÂNCIAS HÚMICAS EM LATOSSOLO SUBMETIDO A APLICAÇÃO CONTÍNUA DE LODO DE ESGOTO(1)
}

\author{
Bruno de Oliveira Dias ${ }^{(2)}$, Carlos Alberto Silva ${ }^{(3)}$, Emanuelle Mercês \\ Barros Soares $^{(4)} \&$ Wagner Bettiol ${ }^{(5)}$
}

\begin{abstract}
RESUMO
Este estudo teve como objetivo avaliar o efeito da aplicação contínua de doses de lodo de esgoto oriundo da Estação de Tratamento de Esgoto de Barueri, SP, sobre os teores e estoques de $\mathrm{C}$ e sobre as alterações na distribuição de substâncias húmicas em Latossolo Vermelho distroférrico. O experimento foi instalado em 1999, no Campo Experimental da Embrapa Meio Ambiente, em Jaguariúna-SP; os dados foram obtidos após a sexta aplicação de lodo e cultivo sucessivo de milho. Foram utilizadas, nas diferentes parcelas experimentais, as seguintes doses acumuladas de lodo de esgoto (base seca): $0,30,60,120$ e $240 \mathrm{Mg} \mathrm{ha}^{-1}$, sendo estudados os tratamentos: (L0) testemunha sem adição de lodo; e aplicação de lodo de esgoto visando fornecer uma (L1), duas (L2), quatro (L4) e oito (L8) vezes a dose de $\mathrm{N}$ requerida pelo milho. Foram avaliados os teores e o estoque de $\mathrm{C}$ orgânico nas camadas de solo de 0-10, 10-20, 20-40 e 40-60 cm. Os teores de $\mathrm{C}$ associados às substâncias húmicas foram avaliados na camada de solo de $0-10 \mathrm{~cm}$. O teor e o estoque de $\mathrm{C}$ orgânico aumentaram com o acréscimo nas doses de lodo de esgoto aplicadas, até a camada de solo de 0-20 cm. A maior parte (50-66 \%) do C associado
\end{abstract}

\footnotetext{
(1) Parte da Tese de Mestrado do primeiro autor apresentada ao Curso de Pós-Graduação em Agronomia, Solos e Nutrição de Plantas, Departamento de Ciência do Solo, Universidade Federal de Lavras - UFLA. Recebido para publicação em julho de 2005 e aprovado em abril de 2007.

(2) Engenheiro-Agrônomo, MSc., Doutorando em Ciência do Solo, Universidade Federal de Lavras - UFLA. Caixa Postal 3037 , CEP 37200-000 Lavras (MG). E-mail: b2dias@yahoo.com.br

(3) Professor do Departamento de Ciência do Solo, UFLA. E-mail: csilva@ufla.br

(4) Doutoranda em Agronomia, Solos e Nutrição de Plantas, Universidade Federal de Viçosa - UFV. E-mail: mercessoares@yahoo.com.br

${ }^{(5)}$ Pesquisador da Embrapa Meio Ambiente. Rod. SP 340, Km 127,5, Caixa Postal 69, CEP 13820-000 Jaguariúna (SP). Bolsista do CNPq. E-mail: bettiol@cnpma.embrapa.br
} 
às substâncias húmicas está presente no solo na forma de humina, seguido por Cfração ácidos fúlvicos e C-fração ácidos húmicos, nesta ordem. A aplicação de lodo de esgoto implica maior acúmulo de substâncias húmicas no solo, mas as proporções de C-humificado da matéria orgânica não são alteradas.

Temos para indexação: matéria orgânica, Zea mays L., ácidos húmicos, ácidos fúlvicos.

\title{
SUMMARY: ORGANIC CARBON STOCK AND QUANTIFICATION OF HUMIC SUBSTANCES OF AN OXISOL UNDER CONTINUOUS SEWAGE SLUDGE APPLICATION
}

\begin{abstract}
This study was carried out to evaluate the effect of continuous sewage sludge applications (Sewage Treatment Station of Barueri, São Paulo State, Brazil) on the C content and stock and on the distribution of C-humic fractions of a Red Latosol (Oxisol). The experiment was installed in 1999 on an experimental field of Embrapa Environment, in Juaguariuna (SP). The data were collected after the sixth sludge application (SS) with corn cultivation. The following accumulated $S S$ doses (dry base) were tested: 0, 30, 60, 120,

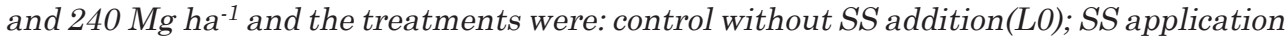
to supply one (L1), two (L2), four (L4) and eight (L8) times the N corn requirement. Carbon contents and stocks were evaluated in the soil layers $0-10,10-20,20-40$ and 40-60 cm, and the $C$ associated to humic substances $0-10 \mathrm{~cm}$ deep. As the $S S$ applications increased, the $C$ content and stock rose in the $0-20 \mathrm{~cm}$ soil layer. Most soil C (50-66\%) is associated to the humin pool, followed by fulvic acid fraction- $C$ and then humic acid fraction- $C$. Sewage sludge applications result in higher contents of $C$-humic substances in soil, though the proportion of mineralized $C$ in soil humus remained unchanged.
\end{abstract}

Index terms: organic matter, Zea mays L., humic acids, fulvic acids.

\section{INTRODUÇÃO}

O lodo de esgoto, gerado nas Estações de Tratamento de Esgoto (ETEs), necessita de adequada disposição para não se converter em um problema ambiental. Entretanto, esse resíduo só pode ser utilizado na agricultura se estiver dentro de padrões mínimos exigidos pelos órgãos ambientais quanto à presença de metais pesados e patógenos humanos, entre outros (Bettiol \& Camargo, 2001; Conama, 2006). Dentre as diversas opções de disposição do lodo, o uso agrícola tem se destacado, por reduzir a pressão de exploração sobre os recursos naturais, viabilizar a ciclagem de nutrientes, promover a melhoria das condições químicas, físicas e biológicas dos solos (Berton et al., 1989; Oliveira, 2000; Simonete, 2001) e introduzir e aumentar o teor de matéria orgânica no solo (Rocha et al., 2004).

A construção de novas estações de esgoto e a ampliação das já existentes e, por conseguinte, o maior uso de lodo de esgoto em áreas agrícolas podem constituir-se em alternativas eficientes para o maior seqüestro de carbono no solo, o aumento da produção de biomassa vegetal e a melhoria do grau de fertilidade de solos brasileiros. Isso ocorre em razão de o carbono estar presente no lodo em altas concentrações, com teores variando de 18 a $50 \%$ na matéria seca desse resíduo (Boyd et al., 1980). Entretanto, o aporte de C e de substâncias húmicas no solo é regulado pela composição química do lodo, que é muito variável e depende da origem do esgoto, do sistema de tratamento de efluentes utilizados nas estações de tratamento e do tempo de compostagem (Albiach et al., 2001; Zbytniewski \& Buszewski, 2005).

Assim, em solos que recebem lodo de esgoto, o aumento nos teores de $\mathrm{C}$ orgânico depende da dose aplicada, da taxa de decomposição e de características intrínsecas aos diferentes lodos (Oliveira et al., 2002). Em regiões tropicais, os efeitos da adição de lodo de esgoto sobre o C orgânico, quando ocorrem, são temporários (Carmo, 2001; Vaz \& Gonçalves, 2002), porém, em alguns estudos, têm-se verificado, em longo prazo, aumentos lineares desses teores no solo com a aplicação de doses crescentes de lodo de esgoto (Marques, 1996; Oliveira et al., 2002).

$\mathrm{O}$ potencial de seqüestro de $\mathrm{C}$ no solo depende, em parte, das características químicas e da resistência do lodo à decomposição microbiana. O lodo é constituído por diferentes grupos orgânicos, entre eles as substâncias húmicas, que são consideradas o estádio final da evolução dos compostos de $\mathrm{C}$ no solo (Stevenson, 1994), sendo, portanto, um grupo de 
substâncias mais estáveis e de difícil degradação do ponto vista químico, o que pode representar uma reserva de C no solo (Yang et al., 2004). Por ser um material humificado, o lodo de esgoto pode contribuir para o aumento dos teores e proporções de substâncias húmicas presentes no solo, principalmente de ácidos fúlvicos, o que pode ser verificado no estudo de Sastre et al. (1996), em que a relação de C-ácidos húmicos/Cácidos fúlvicos caiu de 0,6 (solo não tratado com lodo) para 0,31, na área onde esse resíduo foi adicionado ao solo na dose de $100 \mathrm{t} \mathrm{ha}^{-1}$. Por sua vez, em estudo de seis semanas de incubação de solos com lodo, Iakimenko et al. (1996) não observaram grandes mudanças na composição do húmus do solo. De acordo com Albiach et al. (2001), o acréscimo no teor de C orgânico do solo depende da dose e da composição química do lodo de esgoto aplicado.

As características químicas e estruturais da matéria orgânica, bem como suas interações com a fração mineral, determinam a suscetibilidade à decomposição e o seu grau de estabilização química (Dick et al., 2001). Segundo Bernal et al. (1998), as taxas de degradação de lodo de esgoto após aplicação no solo podem ser inferiores a $20 \%$ do $\mathrm{C}$ total adicionado. Esses valores refletem a presença de compostos orgânicos de difícil degradação biológica no lodo, como óleos, graxas e outras moléculas mais recalcitrantes (Santos et al., 2002). As diferentes frações de $\mathrm{C}$ orgânico humificado do solo apresentam características químicas, físicas e morfológicas diferenciadas entre si, e a distribuição dessas frações no solo pode indicar a qualidade da matéria orgânica (Canellas et al., 2003).

Pela importância que a matéria orgânica exerce no que diz respeito à sustentabilidade de ecossistemas e em razão das alterações que diferentes sistemas de uso e manejo de solo exercem sobre a dinâmica do C, sobre o grau de fertilidade de solos e sobre o efeito estufa, torna-se necessária a realização de ações de pesquisas no sentido de verificar quais as práticas que mais contribuem para aumentar o armazenamento de matéria orgânica no solo. Assim, este estudo teve como objetivo avaliar o teor e o estoque de $\mathrm{C}$ e possíveis alterações na distribuição das frações húmicas da matéria orgânica de um Latossolo Vermelho distroférrico cultivado com milho e submetido a aplicações sucessivas de doses crescentes de lodo de esgoto.

\section{MATERIAL E MÉTODOS}

As amostras de solo foram coletadas no Campo Experimental da Embrapa Meio Ambiente, localizado em Jaguariúna-SP, na latitude de $22^{\circ} 41^{\prime}$ sul, longitude de $47^{\circ} \mathrm{W}$ Gr. e altitude de $570 \mathrm{~m}$, em área de Latossolo Vermelho distroférrico de textura argilosa.
O lodo de esgoto utilizado no experimento foi o oriundo da Estação de Tratamento de Esgoto de Barueri, $\mathrm{SP}$, que trata esgoto doméstico e industrial. Antes da aplicação no campo, foi coletada uma amostra representativa de cada partida dos lodos de esgoto usados nos diferentes cultivos do milho, para avaliação de suas composições químicas (Quadro 1).

O experimento foi constituído por cinco tratamentos, distribuídos num delineamento em blocos casualizados com três repetições, sendo utilizadas parcelas experimentais de $10 \times 20 \mathrm{~m}$, perfazendo uma área de $200 \mathrm{~m}^{2}$ cultivada com milho. Os tratamentos avaliados foram: testemunha sem adição de lodo (L0); e aplicação de lodo de esgoto visando suprir uma (L1), duas (L2), quatro (L4) e oito (L8) vezes a dose de N aplicada em L1. As doses de lodo de esgoto, aplicadas em base seca, foram calculadas tendo como base os teores de $\mathrm{N}$ total e de $\mathrm{N}$ mineral presentes no lodo, no caso do terceiro, quinto e sexto cultivos de milho. $\mathrm{O}$ índice de conversão de $\mathrm{N}$ orgânico em N mineral utilizado no cálculo foi de 30 \%, considerando-se, assim, uma taxa de mineralização de $30 \%$ do N orgânico presente no lodo, seguindo as recomendações da Norma P 4230 (CETESB, 1999). $\mathrm{O}$ requerimento de $\mathrm{N}$ pelo milho foi calculado considerando-se a classe de resposta média ao $\mathrm{N}$ aplicado e a produtividade esperada, na faixa de $6-8 \mathrm{t}$ ha $^{-1}$ de grãos (Raij et al., 1997). Nos tratamentos em que o lodo de esgoto foi aplicado, foi feita, quando necessária, uma suplementação com $\mathrm{KCl}$ para fornecer a quantidade de $\mathrm{K}$ adequada ao milho no plantio. No quadro 2 são apresentadas as doses de lodo de esgoto e de K utilizadas no experimento, por tratamento e ciclo de cultivo de milho, e as doses acumuladas no período.

O estudo da Embrapa Meio Ambiente foi implantado em 1999 e, desde então, tem sido anualmente adubado com doses crescentes de lodo de esgoto oriundo da ETE Barueri. Até o presente estudo, já foram realizados seis cultivos sucessivos com milho, sendo aplicadas doses acumuladas de lodo que corresponderam, em base seca, a: $0 \mathrm{Mg} \mathrm{ha}^{-1}$ (L0), $30 \mathrm{Mg} \mathrm{ha}^{-1}$ (L1), $60 \mathrm{Mg} \mathrm{ha}^{-1}$ (L2), $120 \mathrm{Mg} \mathrm{ha}^{-1}$ (L4) e $240 \mathrm{Mg} \mathrm{ha}^{-1}$ (L8). Após cada ciclo de cultivo de milho, os restos culturais foram retirados da área experimental, no sentido de não haver interferência na análise do efeito de doses de lodo de esgoto sobre os teores de matéria orgânica do solo.

O lodo de esgoto foi distribuído a lanço em área total das parcelas experimentais e incorporado ao solo a uma profundidade de $20 \mathrm{~cm}$, com o auxílio de enxada rotativa e arado de disco. Para as determinações laboratoriais, as amostras de solo foram coletadas 60 dias após a sexta aplicação de lodo, nas profundidades de solo de 0-10, 10-20, 20-40 e 40-60 cm, secas ao ar e, em seguida, moídas, passadas em peneira de $2 \mathrm{~mm}$ e caracterizadas quimicamente (Quadro 3), seguindo-se protocolos analíticos descritos em Silva (1999). 
Quadro 1. Características químicas dos lotes de lodo de esgoto utilizados no tratamento do solo, em seis ciclos de cultivo de milho

\begin{tabular}{|c|c|c|c|c|c|c|c|}
\hline \multirow{2}{*}{ Atributo } & \multirow{2}{*}{ Unidade $^{(1)}$} & \multicolumn{6}{|c|}{ Cultivo de milho } \\
\hline & & $1^{\circ}$ & $2^{\circ}$ & $3^{\mathrm{o}}$ & $4^{\circ}$ & $5^{\circ}$ & $6^{\circ}$ \\
\hline pH ( água) & & 6,6 & 6,4 & 6,4 & 8,5 & 8,0 & 8,3 \\
\hline Teor de água ${ }^{(2)}$ & $\%$ & 66,4 & 80,2 & 71,2 & 79,5 & 78,8 & 81,2 \\
\hline Sólidos voláteis & $\%$ & 43,0 & nd & 56,8 & 62,6 & 59,6 & 62,0 \\
\hline C orgânico & $\mathrm{g} \mathrm{kg}^{-1}$ & 248 & 271 & 293 & 354 & 534 & 312 \\
\hline $\mathrm{N}$ total $^{(2)}$ & $\mathrm{g} \mathrm{kg}^{-1}$ & 21 & 49,7 & 42,1 & 40,8 & 79,7 & 43,5 \\
\hline N-amoniacal & $\mathrm{mg} \mathrm{kg}^{-1}$ & 1.567 & 1.156 & 2.402 & 2.095 & 2.301 & nd \\
\hline $\mathrm{N}$-nítrico & $\mathrm{mg} \mathrm{kg}^{-1}$ & 106 & 106 & 51 & 15 & 23 & nd \\
\hline $\mathrm{P}$ & $\mathrm{g} \mathrm{kg}^{-1}$ & 15,9 & 31,2 & 26,9 & 17,7 & 17,9 & 16,1 \\
\hline $\mathrm{K}$ & $\mathrm{g} \mathrm{kg}^{-1}$ & 1,0 & 2,0 & 1,0 & 1,5 & 1,0 & 1,2 \\
\hline $\mathrm{Ca}$ & $\mathrm{g} \mathrm{kg}^{-1}$ & 40,3 & 22,8 & 47,8 & 20,1 & 19,4 & 13,4 \\
\hline $\mathrm{Mg}$ & $\mathrm{g} \mathrm{kg}^{-1}$ & 3,0 & 3,7 & 4,5 & 3,7 & 3,8 & 2,7 \\
\hline $\mathrm{Na}$ & $\mathrm{g} \mathrm{kg}^{-1}$ & 0,5 & 0,6 & 0,5 & 0,5 & 0,9 & 0,6 \\
\hline $\mathrm{S}$ & $\mathrm{g} \mathrm{kg}^{-1}$ & 13,4 & 10,8 & 17,1 & 11,7 & 14,5 & 12,6 \\
\hline $\mathrm{Fe}$ & $\mathrm{g} \mathrm{kg}^{-1}$ & 54,2 & 32,5 & 38,0 & 39,1 & 32,1 & 31,9 \\
\hline Mo & $\mathrm{mg} \mathrm{kg}^{-1}$ & $<0,01$ & $<1$ & $<0,01$ & $<0,01$ & $<0,1$ & $<0,01$ \\
\hline $\mathrm{Mn}$ & $\mathrm{mg} \mathrm{kg}^{-1}$ & 430 & 335 & 419 & 278 & 247 & 209 \\
\hline $\mathrm{Cu}$ & $\mathrm{mg} \mathrm{kg}^{-1}$ & 1.058 & 1.046 & 953 & 682 & 868 & 805 \\
\hline $\mathrm{Zn}$ & $\mathrm{mg} \mathrm{kg}^{-1}$ & 2.821 & 3.335 & 3.372 & 2.328 & 3.330 & 2.888 \\
\hline B & $\mathrm{mg} \mathrm{kg}^{-1}$ & 36,2 & 11,2 & 29,3 & 10,7 & 17,6 & 11,1 \\
\hline Cr total & $\mathrm{mg} \mathrm{kg}^{-1}$ & 823 & 1071 & 1297 & 609 & 640 & 700 \\
\hline $\mathrm{Ni}$ & $\mathrm{mg} \mathrm{kg}^{-1}$ & 518 & 483 & 606 & 331 & 270 & 253 \\
\hline $\mathrm{Al}$ & $\mathrm{mg} \mathrm{kg}^{-1}$ & 28,8 & 25,3 & 23,3 & 11,9 & 14,2 & 15,1 \\
\hline $\mathrm{Cd}$ & $\mathrm{mg} \mathrm{kg}^{-1}$ & 12,8 & 9,5 & 9,4 & 16,2 & 14,0 & 14,1 \\
\hline $\mathrm{Pb}$ & $\mathrm{mg} \mathrm{kg}^{-1}$ & 364 & 233 & 349 & 138 & 149 & 127 \\
\hline As & $\mathrm{mg} \mathrm{kg}^{-1}$ & $<1$ & $<1$ & $<1$ & $<0,01$ & $<0,1$ & $<0,01$ \\
\hline $\mathrm{Ag}$ & $\mathrm{mg} \mathrm{kg}^{-1}$ & $<0,01$ & $<1$ & $<0,01$ & $<0,01$ & $<0,1$ & $<0,01$ \\
\hline
\end{tabular}

Quadro 2. Quantidades de lodo de esgoto e $\mathrm{K}_{2} \mathrm{O}$ aplicadas nos seis cultivos de milho

\begin{tabular}{|c|c|c|c|c|c|c|c|c|c|c|c|c|c|}
\hline \multirow{3}{*}{ Tratamento $^{(1)}$} & \multicolumn{7}{|c|}{ Lodo de esgoto, base seca } & \multicolumn{6}{|c|}{$\mathbf{K}_{2} \mathbf{O}^{(2)}$} \\
\hline & \multicolumn{6}{|c|}{ Cultivo } & \multirow{2}{*}{ Total } & \multicolumn{6}{|c|}{ Cultivo } \\
\hline & $1^{\circ}$ & $2^{\circ}$ & $3^{o}$ & $4^{\circ}$ & $5^{\circ}$ & $6^{\circ}$ & & $1^{\circ}$ & $2^{\circ}$ & $3^{\circ}$ & $4^{\circ}$ & $5^{\circ}$ & $6^{\circ}$ \\
\hline
\end{tabular}

\begin{tabular}{|c|c|c|c|c|c|c|c|c|c|c|c|c|c|}
\hline \multirow[b]{2}{*}{ L0 } & \multicolumn{6}{|c|}{$\mathrm{Mg} \mathrm{ha}^{-1}$} & \multirow[b]{2}{*}{0} & \multicolumn{6}{|c|}{$\mathrm{kg} \mathrm{ha}^{-1}$} \\
\hline & 0 & 0 & 0 & 0 & 0 & 0 & & - & - & - & - & - & - \\
\hline L1 & 8 & 4 & 5,6 & 5,6 & 3 & 3,8 & 30 & 3 & 28 & 40 & 87 & 57 & 36 \\
\hline L2 & 16 & 8 & 10,9 & 10,9 & 6,5 & 7,7 & 60 & - & 19 & 8 & 69 & 45 & 21 \\
\hline L4 & 32 & 16 & 21,5 & 21,5 & 13 & 16 & 120 & - & 4 & - & 33 & 21 & - \\
\hline L8 & 64 & 32 & 43 & 43 & 26 & 32 & 240 & - & - & - & - & - & - \\
\hline
\end{tabular}

${ }^{(1)} \mathrm{L} 0, \mathrm{~L} 1, \mathrm{~L} 2, \mathrm{~L} 4$ e L8 = doses de lodo de esgoto equivalentes a 0, 30, 60, 120 e 240 t ha $^{-1}$ (base seca), respectivamente. (2) Quantidade de $\mathrm{K}_{2} \mathrm{O}$ utilizada para complementar o $\mathrm{K}$ fornecido pelo lodo de esgoto e atender às exigências nutricionais do milho. 
Quadro 3. Caracterização química das amostras de solo do experimento, coletadas após a sexta aplicação de lodo de esgoto

\begin{tabular}{|c|c|c|c|c|c|c|c|c|c|}
\hline Tratamento ${ }^{(1)}$ & $\mathbf{p H}^{(2)}$ & $\mathbf{P}^{(3)}$ & $\mathbf{K}$ & $\mathrm{Ca}^{+2}$ & $\mathrm{Mg}^{+2}$ & $\mathrm{Al}^{+3}$ & $\mathrm{H}+\mathrm{Al}$ & $\mathbf{T}$ & V \\
\hline & & \multicolumn{2}{|c|}{$-\mathrm{mg} \mathrm{dm}^{-3}$} & \multicolumn{5}{|c|}{$\mathrm{cmol}_{\mathrm{c}} \mathrm{dm}^{-3}$} & $\%$ \\
\hline L0 & 5,6 & 1,9 & 32,3 & 2,7 & 1,6 & 0,3 & 4,9 & 9,3 & 47 \\
\hline $\mathrm{L} 1$ & 5,6 & 21,8 & 40,0 & 3,8 & 1,4 & 0,1 & 4,8 & 10,1 & 52 \\
\hline $\mathrm{L} 2$ & 5,9 & 62,8 & 35,3 & 4,6 & 1,6 & 0 & 4,0 & 10,3 & 61 \\
\hline $\mathrm{L} 4$ & 5,8 & 113,6 & 30,3 & 5,0 & 1,5 & 0 & 4,8 & 11,4 & 57 \\
\hline L8 & 5,2 & 175,1 & 44,7 & 4,8 & 1,4 & 0,2 & 5,9 & 12,2 & 52 \\
\hline
\end{tabular}

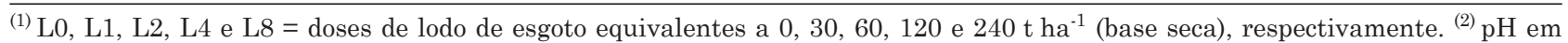
água: relação solo:água $(1: 2,5) .{ }^{(3)}$ P-Mehlich-1.

O teor de C orgânico nas amostras foi determinado pelo método proposto por Yeomans \& Breemner (1988), cujo princípio é a oxidação do $\mathrm{C}$ orgânico a quente com dicromato de potássio e titulação do dicromato remanescente com sulfato ferroso amoniacal. O estoque de $\mathrm{C}$ foi obtido pelo uso da expressão: teor de $\mathrm{C}$ $\left(\mathrm{g} \mathrm{kg}^{-1}\right) \mathrm{x}$ densidade do solo $\left(\mathrm{kg} \mathrm{dm}^{-3}\right)$ x espessura da camada do solo $(\mathrm{cm})$. A densidade, em cada profundidade do solo, foi determinada com auxílio de cilindros de aço de $4 \mathrm{~cm}$ de diâmetro e $4 \mathrm{~cm}$ de altura.

Para avaliar a qualidade da matéria orgânica, utilizou-se o método de extração e fracionamento quantitativo de substâncias húmicas descrito por Benites et al. (2003). Com base na solubilidade diferenciada das substâncias húmicas em meios alcalino e ácido, foram determinados os teores de $\mathrm{C}$ associados à fração ácidos húmicos (C-FAH), à fração ácidos fúlvicos (C-FAF) e à humina (C-HU). Na etapa de extração, foi utilizada solução de $\mathrm{NaOH} 0,1 \mathrm{~mol} \mathrm{~L}^{-1}$, na relação solo:extrator de 1:10 p/v. A extração se estendeu por um período de $24 \mathrm{~h}$, e a separação da fração ácidos húmicos + fração ácidos fúlvicos, denominada extrato alcalino (EA), e a do solo remanescente, denominado humina (HU), foram feitas por centrifugação a $9.000 \mathrm{rpm}$ por $10 \mathrm{~min}$, seguida de duas lavagens do resíduo com a mesma solução, adicionando-se os extratos aos materiais anteriormente reservados. Ao término das extrações, o material remanescente no frasco foi seco, peneirado (malha de $2 \mathrm{~mm}$ ) e utilizado na determinação do $\mathrm{C}$ na forma de humina (C-HU). Na seqüência, o extrato alcalino (C-FAH + C-FAF) teve o $\mathrm{pH}$ ajustado para $1,5 \pm 0,5$ com $\mathrm{H}_{2} \mathrm{SO}_{4}$ a $20 \%$, permanecendo, em seguida, em repouso por $18 \mathrm{~h}$, até a decantação do precipitado formado. O precipitado denominado de fração ácidos húmicos (FAH) foi separado da fração solúvel, fração ácidos fúlvicos (FAF), por filtração, utilizando-se sistema Millipore de filtragem de $47 \mathrm{~mm}$ de diâmetro e filtro de $0,45 \mu \mathrm{m}$. A FAH foi rediluída em solução de $\mathrm{NaOH} 0,1 \mathrm{~mol} \mathrm{~L}^{-1}$ e teve o volume completado para $50 \mathrm{~mL}$; já o volume da FAF foi ajustado para $50 \mathrm{~mL}$, utilizando-se água destilada. $\mathrm{Na}$ determinação do teor de C orgânico nas frações HU, FAH e FAF, seguiu-se a mesma marcha analítica descrita por Yeomans \& Bremner (1988). Para as frações AH e AF, utilizou-se uma alíquota de $5 \mathrm{~mL}$ de solução do extrato obtido no fracionamento. Foram calculadas as relações entre os teores de $\mathrm{C}$ associados às frações ácidos húmicos e ácidos fúlvicos (C-FAH/C$\mathrm{FAF}$ ) e as relações entre os teores de $\mathrm{C}$ no extrato alcalino (C-fração ácidos húmicos + C-fração ácidos fúlvicos) e na humina (C-humina).

Os dados obtidos foram submetidos à análise de variância e de regressão, utilizando-se as três repetições de campo, com o nível de significância de $1 \%$; foi empregado nessa etapa o programa estatístico SISVAR (Ferreira, 2003).

\section{RESULTADOS E DISCUSSÃO}

Os teores de $\mathrm{C}$ orgânico aumentaram de modo significativo $(\mathrm{P}<0,001)$ nas camadas de solo de $0-10$ e 10-20 cm, em razão do acréscimo das doses aplicadas de lodo de esgoto (Figura 1). Os valores médios de $\mathrm{C}$ orgânico no solo (0-10 cm), nos tratamentos que não receberam lodo, foram de $19,6 \mathrm{~g} \mathrm{~kg}^{-1}$, enquanto nos solos que receberam oito vezes a dose recomendada de lodo (dose acumulada de $240 \mathrm{Mg} \mathrm{ha}^{-1}$, base seca) os teores médios foram de $33,5 \mathrm{~g} \mathrm{~kg}^{-1}$. Assim, após o sexto cultivo sucessivo com milho, a aplicação contínua de lodo de esgoto, considerando-se a maior dose testada, proporcionou, em relação à testemunha, aumento médio de $0,058 \mathrm{~g} \mathrm{~kg}^{-1}$ no teor de $\mathrm{C}$ orgânico por cada tonelada de lodo aplicada na camada superficial do Latossolo estudado.

A possibilidade de manutenção ou aumento nos teores de $\mathrm{C}$ dos solos em função da aplicação de lodo de esgoto já foi verificada por Fernandes et al. (2005), em estudo realizado na mesma área do presente 


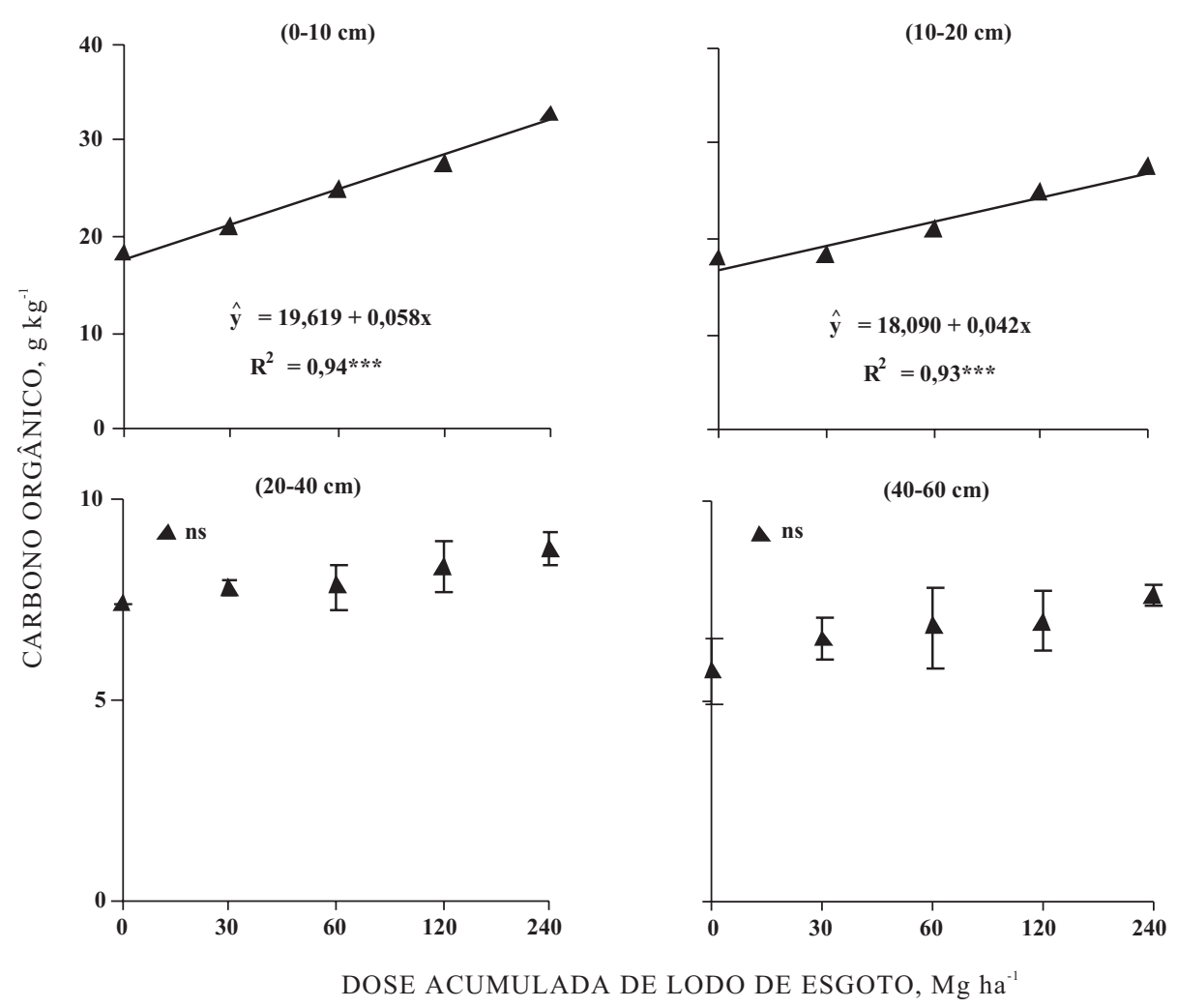

Figura 1. Teores de C orgânico em Latossolo sucessivamente tratado com lodo de esgoto, nas profundidades de 0-10, 10-20, 20-40 e 40-60 cm. (***: Significativo a 0,1\%). As barras verticais referem-se ao desviopadrão da média.

trabalho, até a quarta aplicação do resíduo, sendo observado que a utilização de lodo de esgoto por longo período de tempo resultou em maior acúmulo de $\mathrm{C}$ no solo. Rocha et al. (2004), avaliando os efeitos de doses crescentes de lodo de esgoto na fertilidade de um Latossolo Vermelho-Amarelo distrófico na cultura do eucalipto, observaram que, 32 meses depois da aplicação, houve aumento nos teores de C orgânico com o acréscimo das doses de lodo usadas, em comparação com o tratamento testemunha e com o que recebeu apenas adubação mineral, sendo esse maior acúmulo verificado nas camadas de solo de 5-10 e 10-20 cm.

Neste estudo, nas camadas de solo de 20-40 e 40-60 cm, não foram verificadas diferenças estatísticas nos teores de C orgânico dos tratamentos avaliados. A ausência de influência do lodo nos teores de $\mathrm{C}$ em profundidade, possivelmente, deve-se ao fato de o resíduo ter sido aplicado na camada de aração, o que contribui para o maior acúmulo de matéria orgânica na camada superficial. Além disso, os compostos orgânicos, independentemente da origem, possuem baixa mobilidade, movimentando-se pouco no perfil do solo. Em geral, os dados obtidos revelam que o lodo de esgoto proporcionou aumento significativo nos teores de $\mathrm{C}$ orgânico do solo na camada de 0-20 cm. $\mathrm{O}$ armazenamento de $\mathrm{C}$ foi significativamente maior $(\mathrm{P}<0,001)$ nos tratamentos com maiores doses de lodo de esgoto, em comparação com a testemunha, com os estoques variando nesses tratamentos de 24,9 a 43,2 $\mathrm{Mg} \mathrm{ha}^{-1}$ e 24,2 a 34,7 $\mathrm{Mg} \mathrm{ha}^{-1}$ nas camadas de solo de 0-10 e 10-20 cm, respectivamente (Figura 2).

O lodo proporcionou incrementos no estoque de $\mathrm{C}$, em relação à testemunha, na camada de $0-10 \mathrm{~cm}$, e esses aumentos foram de aproximadamente 3,0; 4,5; 9,0 e 18,2 $\mathrm{Mg} \mathrm{ha}^{-1}$, nos tratamentos que receberam, respectivamente, 30, 60, 120 e $240 \mathrm{Mg} \mathrm{ha}^{-1}$ (base seca) de lodo de esgoto. $\mathrm{O}$ aumento nos estoques de $\mathrm{C}$ nas camadas de solo de 0-10 e 10-20 cm pode ser justificado pela qualidade e quantidade aplicada do lodo. A composição química do lodo de esgoto e seu grau de humificação dependem do processo de tratamento, de modo que a matéria orgânica de alguns lodos, quando sujeita à intensa decomposição aeróbia e anaeróbia nas estações de tratamento, pode ser relativamente estável do ponto de vista químico, portanto, com maior grau de humificação (Iakimenko et al., 1996). Isso poderia explicar, em parte, o incremento no teor de $\mathrm{C}$ orgânico de solos tratados sucessivamente com esse resíduo, o que poderia ser uma explicação também para o maior acúmulo em solo do material orgânico adicionado (Gerzabek et al., 2001).

O aumento nos teores de $\mathrm{C}$ nas camadas de $0-10 \mathrm{e}$ 10-20 cm tem conseqüência direta sobre os estoques de $\mathrm{C}$. Esse fato pode ter ocorrido devido às aplicações elevadas e contínuas de lodo de esgoto e, possivelmente, 


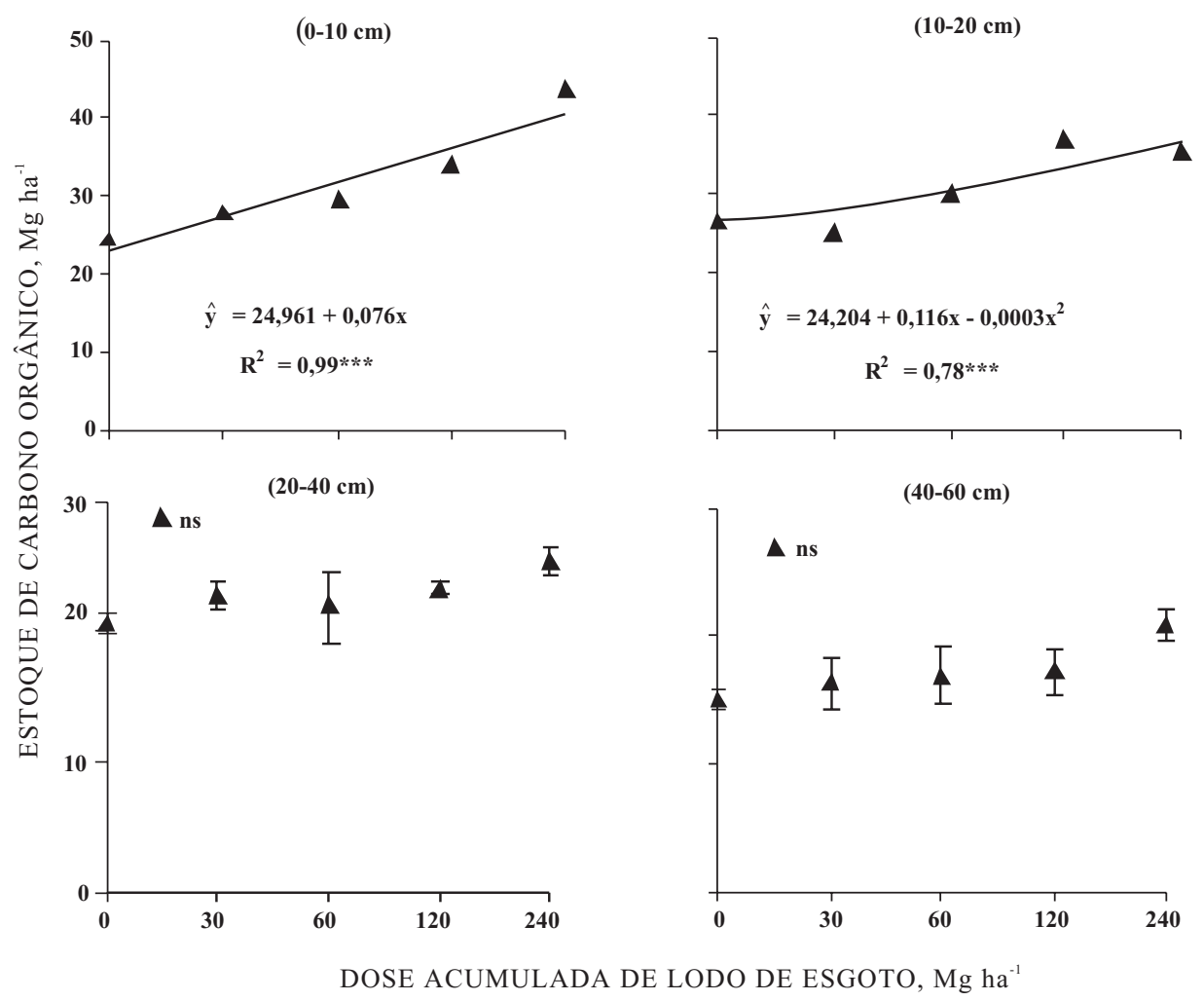

Figura 2. Estoque de carbono orgânico em Latossolo sucessivamente tratado com lodo de esgoto, nas profundidades de 0-10, 10-20, 20-40 e 40-60 cm. (***: Significativo a 0,1 \%). As barras verticais referemse ao desvio-padrão da média.

às menores taxas de mineralização, concordando com os resultados obtidos por Oliveira et al. (2002). Uma outra explicação poderia estar relacionada à maior produção de biomassa vegetal, ocasionando maior aporte de matéria orgânica oriunda da decomposição das raízes do milho que permaneceram no campo após a colheita, uma vez que, neste experimento, a produção de biomassa da parte aérea foi desconsiderada, por ter sido removida das parcelas experimentais em cada ciclo de cultivo.

Nas camadas mais profundas do solo (20-40 e 40-60 cm), não foram verificadas diferenças significativas dos estoques de $\mathrm{C}$ entre os tratamentos (Figura 2). Essa ausência de efeito do lodo sobre o C no subsolo pode estar relacionada com a aplicação do resíduo em superfície e com a baixa movimentação desse elemento no perfil de solo, conforme mencionado anteriormente. A rápida mineralização do C-resíduo nas camadas superficiais de solos de regiões tropicais, em relação aos de regiões mais frias, sem que haja tempo para maior movimentação do $\mathrm{C}$ no perfil do solo, constitui-se em uma outra possível explicação para a grande dificuldade de se aumentar o $\mathrm{C}$ nas camadas de solo de subsuperfície.

Os teores de $\mathrm{C}$ associados às frações ácidos húmicos (C-FAH), ácidos fúlvicos (C-FAF) e humina (C-HU), determinados em amostras de solo de $0-10 \mathrm{~cm}$ de profundidade, são apresentados na figura 3. A aplicação de doses crescentes de lodo de esgoto promoveu modificações nos teores das frações humificadas da matéria orgânica, ocorrendo aumentos significativos nos teores de $\mathrm{C}$ das três frações analisadas.

Na figura 3a são apresentados os teores de C-FAH, que aumentaram com o acréscimo das doses de lodo; observa-se que o melhor ajuste foi obtido pelo modelo linear. O teor médio de C-FAH é de $2,94 \mathrm{~g} \mathrm{~kg}^{-1}$ na testemunha ( $\left.0 \mathrm{Mg} \mathrm{ha}^{-1}\right)$; com o aumento das doses de lodo de esgoto, há incremento do teor de C-FAH, chegando a atingir uma média de $5,34 \mathrm{~g} \mathrm{~kg}^{-1}$ no tratamento em que a dose acumulada de lodo de esgoto foi de $240 \mathrm{Mg} \mathrm{ha}^{-1}$. A elevação no conteúdo de C-FAH pode ser indicador de melhoria da qualidade do húmus ou do incremento da atividade biológica, que promove a síntese de substâncias húmicas mais condensadas, segundo Orlov (1998). Esse aumento no teor de C associado às substâncias húmicas no Latossolo estudado reflete o maior aporte de húmus no solo com a adição de lodo de esgoto, uma vez que esse resíduo é rico em C humificado (Iakimenko et al., 1996). As doses de lodo de esgoto utilizadas também exerceram influência sobre os teores de C-FAF (Figura 3b); a dose acumulada de $240 \mathrm{Mg} \mathrm{ha}^{-1}$ (base seca) foi a que proporcionou maior aumento em relação à testemunha, com incremento de $2,88 \mathrm{~g} \mathrm{~kg}^{-1}$ do C-FAF. 


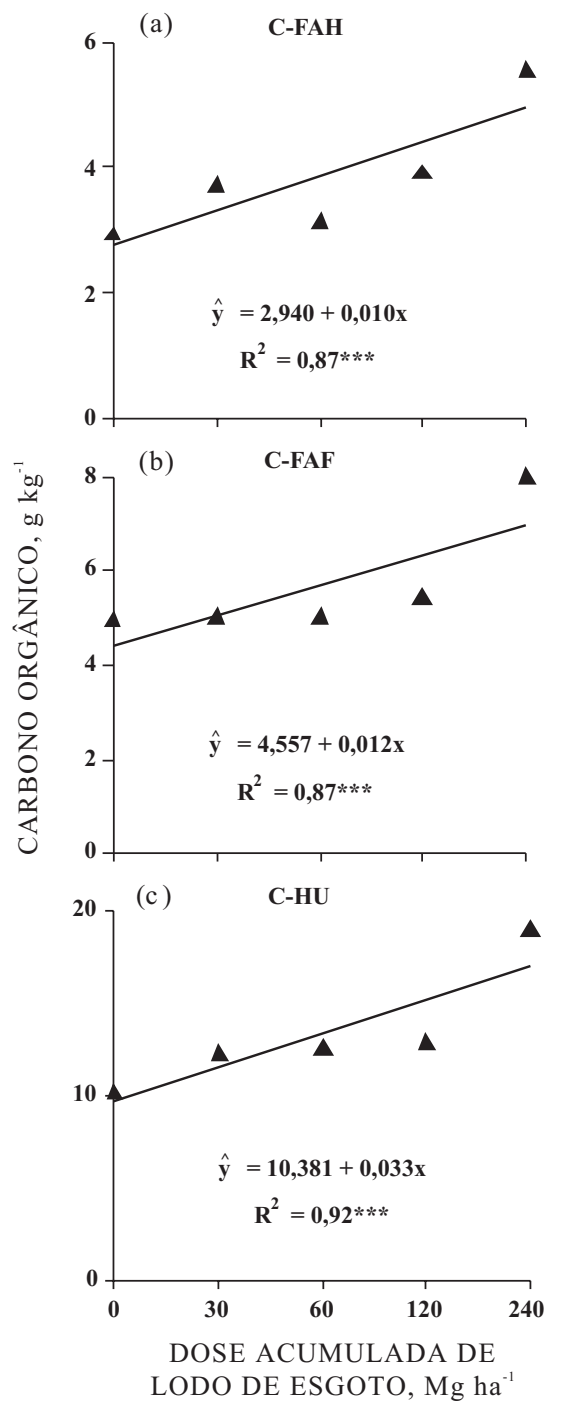

Figura 3. Teores de carbono associados às frações ácido húmico (a), ácido fúlvico (b) e humina (c) em Latossolo sucessivamente tratado com lodo de esgoto. (***: Significativo a 0,1\%).

De modo similar aos teores de C-FAH e C-FAF, foi verificado acréscimo nos teores de $\mathrm{C}$ associados à fração humina (C-HU) com o aumento das doses de lodo de esgoto aplicadas (Figura 3C). Em comparação com o tratamento testemunha, os aumentos no C-HU corresponderam a aproximadamente 0,$99 ; 1,98 ; 3,96$; e $7,92 \mathrm{~g} \mathrm{~kg}^{-1}$, respectivamente, para os tratamentos que receberam 30, 60, 120 e $240 \mathrm{Mg} \mathrm{ha}^{-1}$ (base seca) de lodo de esgoto. Em comparação com as demais frações, o teor de C-HU foi maior, sendo essa maior presença de humina no solo possivelmente relacionada à estabilidade da ligação que existe entre esse componente e a fase mineral do solo, assim como devido a uma maior resistência à decomposição dessa fração húmica (Stevenson, 1982). A aplicação contínua de lodo de esgoto proporcionou aumento no solo de $\mathrm{C}$ associado às substâncias húmicas, de modo que a maior dose de lodo promoveu incrementos de 81,6, 63,2 e 76 \% nos teores de $\mathrm{C}$ associados às frações ácidos húmicos, ácidos fúlvicos e humina, respectivamente, em comparação com o tratamento que não recebeu aplicação do resíduo.

$\mathrm{Na}$ figura 4 são apresentados os resultados relativos à porcentagem de $\mathrm{C}$ em relação ao $\mathrm{C}$ orgânico, para frações ácidos húmicos (C-FAH/C), frações ácidos fúlvicos (C-FAF/C) e humina (C-HU/C), em cada tratamento estudado. Em relação à $\mathrm{C}-\mathrm{FAH} / \mathrm{C}$ (Figura 4a), a aplicação de doses crescentes de lodo promoveu redução do $\mathrm{C}$ associado a essa fração, até a dose de lodo equivalente a $118 \mathrm{Mg} \mathrm{ha}^{-1}$; com o incremento das doses, a contribuição do C-FAH para o C orgânico aumentou, com tendência a superar o tratamento testemunha.

Quanto ao atributo C-FAF/C (Figura 4b), o melhor ajuste para explicar o comportamento dos dados foi o quadrático. As doses de lodo reduziram essa relação quando se aplicaram até $131,5 \mathrm{Mg} \mathrm{ha}^{-1}$, em comparação com a dose testemunha; a partir dessa dose, houve aumento na proporção de $\mathrm{C}$ associado à fração ácidos fúlvicos, os quais são solúveis tanto em meio ácido como em meio alcalino e podem migrar para camadas inferiores do solo (Souza \& Melo, 2003), o que pode causar enriquecimento relativo de ácidos húmicos na camada superficial. Entretanto, comparando os valores obtidos para C-FAF/C orgânico e C-FAH/C orgânico, nos primeiros $10 \mathrm{~cm}$ do solo (Figura $4 \mathrm{a}, \mathrm{b}$ ), verifica-se maior acúmulo de frações ácidos fúlvicos nessa camada, sendo uma possível explicação a predominância de ácidos fúlvicos sobre os ácidos húmicos no lodo de esgoto aplicado no solo. Esse fenômeno também foi observado por Canellas (1999), avaliando alterações na distribuição das frações humificadas em amostras de solo adubadas com lodo de esgoto e composto de lixo urbano.

É possível observar que a relação C-HU/C orgânico (Figura 4c) apresentou comportamento quadrático; o tratamento em que se aplicaram $126,7 \mathrm{Mg} \mathrm{ha}^{-1}$ de lodo promoveu redução desses valores; entretanto, a partir do incremento das doses, houve tendência de o C-HU contribuir mais para o $\mathrm{C}$ orgânico, em relação ao tratamento sem adição de lodo. Dentre todas as frações humificadas, a humina (C-HU) foi a que mais contribuiu para o C orgânico, correspondendo, em média, a 50 a $66 \%$ do C, o que está de acordo com os valores encontrados por outros autores (Leite et al., 2003; Souza \& Mello, 2003), que verificaram, em solo, teores de C-humina englobando de 50 a 78 \% do C orgânico.

Em geral, analisando os dados da figura 4 (C-FAF/ C, C-FAH/C e C-HU/C), observa-se que o aumento nas proporções das substâncias húmicas ocorreu devido ao incremento da humina e dos ácidos fúlvicos. Segundo Canellas et al. (2001), a transformação da matéria orgânica pode não favorecer a formação de ácidos húmicos e, possivelmente, acarretar a estabilização direta, via interação com a fração mineral, ou, ainda, resultar, após a humificação, na dissociação em moléculas menos condensadas. 

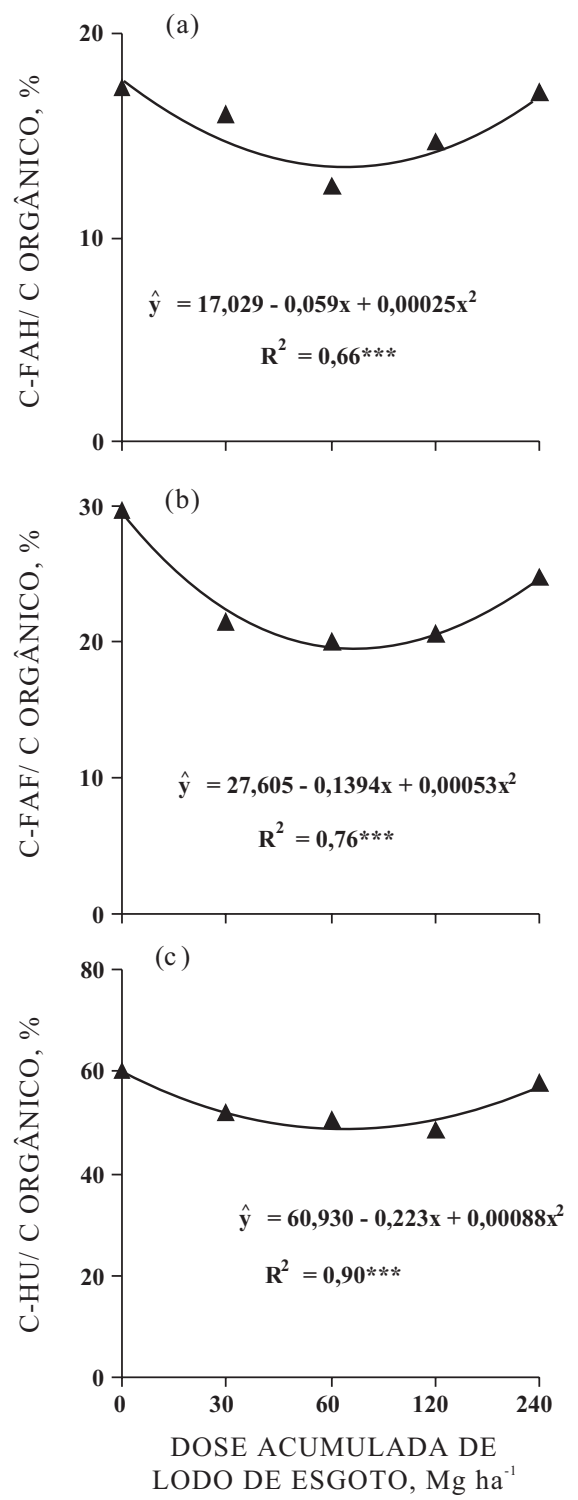

Figura 4. Relação entre as frações ácidos húmicos (a), ácidos fúlvicos (b) e huminas (c) e o carbono orgânico em Latossolo sucessivamente tratado com lodo de esgoto. (***: Significativo a $0,1 \%$ )
As relações entre as frações das substâncias húmicas são apresentadas no quadro 4. A relação entre os teores de $\mathrm{C}$ na forma de ácidos húmicos e ácidos fúlvicos não mostrou diferenças significativas entre os tratamentos. No entanto, observa-se que os dados são inferiores a 1,0, demonstrando predomínio de ácidos fúlvicos na fração humificada. Segundo Canellas (1999), os ácidos fúlvicos são as frações mais reativas, porém com reduzida estabilidade química, indicando uma característica desfavorável, pois podem facilitar, na forma de complexos orgânicos, a lixiviação de cátions e iluviação de argilas humificadas. Em solos tropicais, a intensa mineralização da matéria orgânica e as restrições edáficas à atividade biológica propiciam redução na relação C-AH/C-AF (Benittes et al., 2003). A relação EA/HU não apresentou diferenças significativas entre os tratamentos. Esse índice indica a iluviação da matéria orgânica. Em geral, em horizontes superficiais, as relações EA/HU são menores que 1,0 (Benittes et al., 2003).

\section{CONCLUSÕES}

1. O teor e o estoque de $\mathrm{C}$ orgânico aumentam significativamente na camada superficial de solo (0-20 cm) com o acréscimo nas doses de lodo de esgoto.

2. A aplicação contínua de lodo de esgoto resulta em maior acúmulo de substâncias húmicas no solo, não alterando as proporções de $\mathrm{C}$ entre diferentes compartimentos humificados da matéria orgânica do solo.

\section{AGRADECIMENTOS}

Ao $\mathrm{CNPq}$ pelo financiamento do projeto e pela concessão da bolsa de estudo. E à Embrapa Meio Ambiente, pela contribuição na elaboração, manutenção e condução do estudo.

Quadro 4. Relação entre os teores de carbono na forma de frações ácidos húmicos (C-FAH) e frações ácidos fúlvicos (C-FAF), extrato alcalino (EA) e humina (HU) em Latossolo sucessivamente tratado com doses crescentes de lodo de esgoto

\begin{tabular}{ccc}
\hline Tratamento $^{(1)}$ & C-FAH / C-FAF & EA/HU \\
\hline L0 & & \\
L1 & $0,59 \mathrm{a}$ & $0,78 \mathrm{a}$ \\
L2 & $0,75 \mathrm{a}$ & $0,72 \mathrm{a}$ \\
L4 & $0,62 \mathrm{a}$ & $0,65 \mathrm{a}$ \\
L8 & $0,71 \mathrm{a}$ & $0,73 \mathrm{a}$ \\
\hline
\end{tabular}

(1) L0, L1, L2, L4 e L8 = doses de lodo de esgoto equivalentes a 0, 30, 60, 120 e $240 \mathrm{Mg} \mathrm{ha}^{-1}$ (base seca), respectivamente. ${ }^{(2)}$ Médias seguidas da mesma letra na coluna não diferem entre si pelo teste de Tukey a $5 \%$. 


\section{LITERATURA CITADA}

ALBIACH, R.; CANET, R.; POMARES, F. \& INGELMO, F. Organic matter components, aggregate stability and biological activity in a horticultural soil fertilized with different rates of two sewage sludges during ten years. Biores. Technol., 77:109-114, 2001.

BENITES, V.M.; MÁDARI, B. \& MACHADO, P.L.O.A. Extração e fracionamento quantitativo de substâncias húmicas do solo: um procedimento simplificado e de baixo custo. Rio de Janeiro, Embrapa, 2003. 7p. (Comunicado Técnico, 16)

BERNAL, M.P.; SÁNCHEZ-MONEDERO, M.A.; PAREDES, C. \& ROIG, A. Carbon mineralization from organic wastes at different composting stages during their incubation with soil. Agr. Ecosyst. Environ., 69:175-189, 1998.

BERNAL, M.P.; SÁNCHEZ-MONEDERO, M.A.; PAREDES, C. \& ROIG, A. Carbon mineralization from organic wastes at different composting stages during their incubation with soil.. Nutr. Cycl. Agroec., 70:161-166, 2004.

BERTON, R.S.; CAMARGO, O.A. \& VALADARES, J.M.A.S Absorção de nutrientes pelo milho em resposta à adição de lodo de esgoto a cinco solos paulistas. R. Bras. Ci. Solo, 26:187-192, 1989.

BETTIOL, W. \& CAMARGO, O.A. Reciclagem de lodo de esgoto na agricultura. In: MELO, I.S.; SILVA, C.; SCRAMIN, S. \& SPESSOTO, A., eds. Biodegradação. Jaguariúna, Embrapa Meio Ambiente, 2001. p.93-113.

BOYD, S.A.; SOMMERS, L.E. \& NELSON, D.W. Changes in the humic acid fraction of soil resulting from sludge application. Soil Sci. Soc. Am. J., 44:1179-1186, 1980.

CANELLAS, L.P. Avaliação de características físico-químicas de ácidos húmicos. Seropédica, Universidade Federal Rural do Rio de Janeiro, 1999. 163p. (Tese de Doutorado)

CANELLAS, L.P.; SANTOS, G.A.; RUMJANEK, A.A.M. \& GURIDIO, F. Distribuição da matéria orgânica e características de ácidos húmicos em solos com adição de resíduos de origem urbana. Pesq. Agropec. Bras., 36:15291538, 2001.

CANELLAS, L.P.; VELOSSO, A.C.X.; MARCIANO, C.R.; RAMALHO, J.F.G.P.; RUMJANEK, V.M.; REZENDE, P.B.C. \& SANTOS, G.A. Propriedades químicas de um Cambissolo cultivado com cana-de-açúcar, com preservação do palhiço e adição de vinhaça por longo tempo. R. Bras. Ci. Solo, 27:935-944, 2003.

CARMO, J.B. Impacto da aplicação de biossólidos nas atividades microbianas do solo. Piracicaba, Escola Superior de Agricultura "Luiz de Queiroz", 2001. 105p. (Tese de Mestrado)

COMPANHIA DE TECNOLOGIA DE SANEAMENTO AMBIENTAL - CETESB. Aplicação de lodos de sistemas de tratamento biológico em áreas agrícolas: Critérios para projeto e operação. São Paulo, 1999. 32p. (Manual Técnico, 4230)

CONSELHO NACIONAL DE MEIO AMBIENTE - CONAMA. Resolução 375/2006 que dispõe sobre uso agrícola de lodo de esgoto. Diário Oficial da União 167, seção 1, p.141-146, 30 agosto de 2006 .
DICK, D.P.; GONÇALVES, C.; DALMOLIN, R.; KLAMT, E.; KNICKER, H. \& KÖGEL-KNABNER, I. Características estruturais e distribuição da matéria orgânica em diferentes classes de Latossolos. In: ENCONTRO BRASILEIRO DE SUBSTÂNCIAS HÚMICAS, 4., Viçosa, 2001. Anais. Viçosa, MG, Sociedade Internacional de Substâncias Húmicas, 2001. 2p.

ENVIRONMENTAL PROTECTION AGENCY - EPA. Office of Solid Waste and Emergency Response Test methods for evaluating solid waste, physical/chemical methods. 3.ed. Washington, US Government Printing Office, 1986. (SW-846-3051)

FERNANDES, S.A.P.; BETTIOL, W.; CERRI, C.C. \& CAMARGO, P. Sewage sludge effects on gas fluxes at the soil- atmosphere interface, on soil $\mathrm{d}^{13} \mathrm{C}$ and on total soil carbon and nitrogen. Geoderma, 125:49-57, 2005.

FERREIRA, D.F. SISVAR software: versão 4.6. Lavras, DEX/ UFLA, 2003.

GERZABEK, M.H.; HABERHAUER, G. \& KIRCHMANN, H. Soil organic matter pools and carbon-13 natural abundances in particle-size fractions of a long-term agricultural field experiment receiving organic amendments. Soil Sci. Soc. Am. J., 65:352-358, 2001.

IAKIMENKO, O.; OTABBONG, E.; SADOVNIKOVA, L.; PERSSON, J.; NILSSON, I.; ORLOV, D. \& AMMOSOVA, Y. Dynamic transformation of sewage sludge and farmyard manure components. 1. Content for humic substances and mineralization of organic carbon and nitrogen in incubated soils. Agr. Ecosyst. Environ., 58:121126,1996

LEITE, L.F.C.; MENDONÇA, E.S. NEVES, J.C.L.; MACHADO, P.L.O.A. \& GALVÃO, J.C.C. Estoques totais de carbono orgânico e seus compartimentos em Argissolo sob floresta e sob milho cultivado com adubação mineral e orgânica. R. Bras. Ci. Solo, 25:821-832, 2003.

MARQUES, M.O. Incorporação de lodo de esgoto em solo cultivado com cana-de-açúcar. Jaboticabal, Faculdade de Ciências Agrárias e Veterinária, 1996. 111p. (Tese de Livre Docência)

OLIVEIRA, F.C. Disposição de lodo de esgoto e composto de lixo urbano num Latossolo Vermelho-Amarelo cultivado com cana-de-açúcar. Piracicaba, Escola Superior de Agricultura "Luiz de Queiroz", 2000. 247p. (Tese de Doutorado)

OLIVEIRA, F.C.; MATTIAZZO, M.E.; MARCIANO, C.R. \& ROSSETO, R. Efeitos de aplicações sucessivas de lodo de esgoto em um Latossolo Amarelo distrófico cultivado com cana-de-açúcar: Carbono orgânico, condutividade elétrica, pH e CTC. R. Bras. Ci. Solo, 26:505-519, 2002.

ORLOV, D.S. Organic substances of Russian soils. Eur. Soil Sci., 31:946-953, 1998

RAIJ, B.van; CANTARELLA, H.; QUAGGIO, J.A. \& FURLANI, A.M.C. Recomendações de adubação e calagem para o estado de São Paulo. Campinas, Instituto Agronômico de Campinas, 1997. 285p. 
ROCHA, G.N.; GONÇALVES, J.L.M. \& MOURA, I.M. Mudanças da fertilidade do solo e crescimento de um povoamento de Eucalyptus grandis fertilizado com biossólido. R. Bras. Ci. Solo, 28:623-639, 2004.

SANTOS, D.S.; ANDRADE; C.A. \& MATTIAZZO, M.E. Degradação da fração orgânica de lodos de esgotos após aplicação no solo. In: FERTBIO, Rio de Janeiro, 2002. Anais. Rio de Janeiro, Sociedade Brasileira de Ciência do Solo, 2002. CD-ROM

SASTRE, I.; VICENTE, M.A. \& LOBO, M.C. Influence of the application of sewage sludge on soil microbial activity. Biores. Technol., 57:19-23, 1996.

SILVA, F.C. Manual de análises químicas de solos, plantas e fertilizantes. Brasília, Embrapa/Comunicação para Transferência de Tecnologia, 1999. 370p.

SIMONETE, M.A. Alterações nas propriedades químicas de um Argissolo adubado com lodo de esgoto e desenvolvimento e acúmulo de nutrientes em plantas de milho. Piracicaba, Escola Superior de Agricultura "Luiz de Queiroz", 2001. 89p. (Tese de Doutorado)
SOUZA, W.J.O. \& MELO, W.J. Matéria orgânica em um Latossolo submetido a diferentes sistemas de produção de milho. R. Bras. Ci. Solo, 27:1113-1122, 2003.

STEVENSON, F.J. Humus chemistry: genesis, composition, reactions. 2.ed. New York, John Wiley \& Sons, 1994. $496 \mathrm{p}$.

STEVENSON. F.J. Humus chemistry: genesis, composition, reactions. New York, John Wiley \& Sons, 1982. 443p.

VAZ, L.M.S. \& GONÇALVES, J.L.M. Uso de biossólidos em povoamento de Eucalyptus grandis: Efeito em atributos químicos do solo, no crescimento e na absorção de nutrientes. R. Bras. Ci. Solo, 26:747-758, 2002.

YEOMANS, J.C. \& BREMNER, J.M. A rapid and precise method for routine determination of organic carbon in soil. Comm. Soil Sci. Plant Anal., 19:1467-1476, 1988.

ZBYTNIEWSKI, R. \& BUSZEWSKI, B. Characterization on natural organic matter (NOM) derived from sewage sludge compost. Part 1: chemical and spectroscopic properties. Biores. Technol., 96:471-478, 2005. 